\title{
Improved expression of recombinant fusion defensin gene plasmids packed with chitosan-derived nanoparticles and effect on antibacteria and mouse immunity
}

\author{
XIAOPING WAN $^{1 *}$, JIANLIN CHEN $^{2 *}, \mathrm{CHI} \mathrm{CHENG}^{3 *}$, HUABING ZHANG $^{1}$, \\ SHIJI ZHAO ${ }^{1}$, JIANGLIN LI $^{4}, \mathrm{XUEBIN} \mathrm{LV}^{4}, \mathrm{ZEZHOU} \mathrm{WANG}^{5}$ and RONG GAO ${ }^{1}$
}

\begin{abstract}
${ }^{1}$ Key Laboratory of Bio-Resource and Eco-Environment, Ministry of Education, Key Laboratory of Animal Disease Prevention and Food Safety of Sichuan Province, College of Life Sciences, Sichuan University, Chengdu, Sichuan 610065;

${ }^{2}$ School of Laboratory Medicine, Chengdu Medical College, Chengdu, Sichuan 610500; ${ }^{3}$ College of Bioengineering, Sichuan University of Science \& Engineering, Zigong, Sichuan 643000; ${ }^{4}$ Sichuan Academy of Animal Science, Chengdu, Sichuan 610066; ${ }^{5}$ Center for Animal Disease Control of Sichuan Province, Chengdu, Sichuan 610035, P.R. China
\end{abstract}

Received November 27, 2017; Accepted August 31, 2018

DOI: $10.3892 / \mathrm{etm} .2018 .6716$

\begin{abstract}
In order to develop a secure and competent technique to express the human immune gene for fighting infections, we cloned and expressed the BD2/3 using VR1020 (a eukaryotic expression plasmid). BD2/3 contains human $\beta$-defensin 2 (BD2) and human BD3. To explore safe and effective DNA delivery molecules in vitro and in vivo, the fusion genes of BD2/3 were used as an immune-labelled gene to verify transfection effectivness of modified chitosan (CS). Plasmid of VR1020-BD2/3 was packed with biomaterials: CS, average molecular weight: $25000 \mathrm{D}$; polyethylene glycol-O-chitosan-polyethylenimine (PEG-O-CS-PEI); liposomes (LP); polyamine cationic liposomes (PCL); polyamine cationic liposomes of protamine (PCL-protamine) by ionotropic gelation. We observed that $\mathrm{BD} 2 / 3$ fusion gene showed high bioactivity in vitro and in vivo. The BD2/3 fusion protein inhibited the proliferation of bacteria (S. aureus, S. pneumoniae, $P$. aeruginosa and E. coli). The Kunming mice were immune to these nanoparticles and we analyzed their delivery
\end{abstract}

Correspondence to: Dr Zezhou Wang, Center for Animal Disease Control of Sichuan Province, 30 Jialing Road, Wuhou, Chengdu, Sichuan 610035, P.R. China

E-mail: btrukw@163.com

Dr Rong Gao, Key Laboratory of Bio-Resource and Eco-Environment, Ministry of Education, Key Laboratory of Animal Disease Prevention and Food Safety of Sichuan Province, College of Life Sciences, Sichuan University, Wangjiang Road 29, Chengdu, Sichuan 610065, P.R. China

E-mail: gaorong96@163.com

*Contributed equally

Key words: BD2/3 fusion gene expression, chitosan nanoparticles, mouse, immunity, antimicrobial efficiency and gene expression effect. BD2/3 results in multiple changes of innate and required immune system of mice. BD2/3 increases expression of IgG, IgG1, IgG2a, IL-2, IL-6, IFN- $\gamma$, as well as of lymphocytes and monocytes. Following challenge with virulent $E$. coli, $\mathrm{CD}^{+}{ }^{+}$and $\mathrm{CD}^{+}$positive T-cell counts were highly elevated in the $\mathrm{BD} 2 / 3$ immunized mice, resulting in higher survival rates of mice. These results indicate that nanoparticles containing modified $\mathrm{CS}$ and $\mathrm{BD} 2 / 3$ are potentially safe and effective drugs in vivo to improve the immunity against bacterial infection and enhance innate immunity and adaptive immunity against infectious diseases.

\section{Introduction}

The increasing discovery of multiple antibiotic-resistant bacteria requires urgent development of novel and effective antibacterial reagents (1-3). Natural defensins have attracted attention for their multiple functions against antibiotic resistant bacteria $(4,5)$. Extensive studies have shown that defensins can, not only kill or inhibit the growth of diverse pathogens directly, but also boost specific immune responses that provide highly effective immunity against pathogens $(5,6)$.

Human $\beta$-defensin 2 (BD2) and BD3 are major members of defensin family of antimicrobial peptides (AMP). In addition to their direct bactericidal action, they have been demonstrated to modulate the innate and adaptive immune responses $(4,5,7)$. BD2 acts primarily by its chemotactic ability to recruit memory $\mathrm{T}$ cells and immature dendritic cells, which are key immunological molecules of the immune system during infection or injuries (8). BD2 can also induce mast cell migration, degranulation and histamine release (9). BD3 has been reported to be chemotactic for monocytes and macrophages, which plays an important role in combating infection $(10,11)$. However, single use of BD2 and BD3 as new antimicrobial drugs has to face the deficiency of low bioactivity and short half-time in vivo due to their rapid degradation rate.

Recently, some strategies have been used to overcome the problems of weak bioactivity and half-life period in vivo, such 
as fusion of multiple AMPs (12) and the application of gene delivery systems $(11,13)$. The design of multivalent AMPs usually involves conjugation of several AMP monomers together via linkers, and have been reported to display more novel and stronger bioactivities than the original monomeric forms (14-16). For example, vancomycin, in the form of a component of fusion multivalent antibiotics, has been shown to be more effective against microbes (14) and fusion multivalent indolicidin shows higher bioactivity against multidrug-resistant (MDR) strains (17). These results indicate that fusion of multiple AMPs provides a novel approach for creation of stronger antibiotics to improve the resistance of hosts against infectious disease.

Chitosan (CS) and liposomes (LP) have both been used as gene delivery systems because of their non-toxic, biocompatible properties and efficient DNA loading rates $(18,19)$. However, the nanoparticles containing entrapped genes in CS and LP are rapidly cleared in the blood and are degraded by protease in vivo. To address these problems, LP have been conjugated with amino groups to improve cellular phagocytosis and to promote lysosomal escape due to the positive charge (20). CS has been modified with polyethylene glycol (PEG) and polyethylenimine (PEI) to prolong blood circulation time and enhance escape of DNA from lysosomes $(21,22)$. Such advances in the application of modified CS gene carriers to enhance DNA transfection efficiency in vivo have encouraged further research.

Until now, little information has been available on the synergetic antibacterial effects between $\mathrm{BD} 2$ and $\mathrm{BD} 3$ in vitro and in vivo. Therefore, the present experiment was carried out to compare the delivery efficiency and expression effect of the fusion gene of $\mathrm{BD} 2$ and $\mathrm{BD} 3$ that were entrapped with different LP, CS and its derived package molecules with the aim of developing a safe, effective and biocompatible material to improve the bioactivity of fusion antibacterial peptide gene in vivo against bacterial infection in animals.

\section{Materials and methods}

General. The study was approved by the Ethics Committee of Sichuan University (Chengdu, China).

Construction of prokaryotic expression plasmid of fusion gene of $B D 2 / 3$. To construct a fusion gene of $\mathrm{BD} 2 / 3$ (GenBank: AF071216, AF301470), six oligodeoxynucleotide fragments were designed and synthesized by Sangon Biotech Co., Ltd., Shanghai, China (Table I). The fused gene of BD2/3 was prepared by overlap extension PCR (23). The stop codon of BD3 and the start codon of BD2 were deleted, and restriction sites $B a m \mathrm{HI}, E c o$ RI and $B g l \mathrm{II}$ were added to both ends. The fused BD2/BD3 genes were connected by linker sequence Ser-Ser-Gly-Ser-Gly-Ser. The fusion gene BD2/3 was digested with $B a m \mathrm{HI}$ and EcoRI, and then cloned into the pGEX-4T-1 expression plasmid (Pharmacia Biotech; GE Healthcare, Chicago, IL, USA), a prokaryotic expression vector containing the Tac promoter and a glutathione $\mathrm{S}$ transferase (GST) tag sequence for fusion protein expression. Sequence of the resulting plasmid was confirmed by double restriction enzyme digestions and sequencing, and designated as pGB2B3.
Construction of eukaryotic expression plasmids for fusion $B D 2 / 3$. The recombinant plasmid pGB2B3 was digested with $B a m \mathrm{HI}$ and $B g l \mathrm{II}$, and then the target fragments BD2/3 were ligated to VR1020 expression plasmid (Vical, San Diego, CA, USA). It is a eukaryotic expression vector containing human CMV promoter and a tissue plasminogen activator (TPA) signal sequence for secretion. The correct recombinant plasmid was screened by double restriction enzyme digestions, plasmid PCR and sequencing (data not shown) and then named VRB2B3.

Bioactivity assay in vitro of fusion BD2/3 protein expressed by E. coli. E. coli ( $\mathrm{DH} 5 \alpha$ ) cells transformed with $\mathrm{pGB} 2 \mathrm{~B} 3$ and pGEX-4T-1 were induced with isopropyl- $\beta$-D-thiogalactopyranoside (IPTG) to express the fusion $\mathrm{BD} 2 / 3$ protein which was purified on a GST affinity column (Amersham Biosciences; GE Healthcare). The bioactivity of the fusion protein was measured by inhibition of 4 standard pathogen strains (E. coli ATCC25922, S. aureus ATCC 26112, S. pneumoniae ATCC49619 and P. aeruginosa ATCC10211).

Minimum inhibition concentration (MIC), minimal bactericide concentration (MBC) of fusion BD2/3 protein expressed by $E$. coli. Broth dilution methods were carried out to determine the MIC of fusion $\mathrm{BD} 2 / 3$ protein against bacterial cultures of $5 \times 10^{5} \mathrm{CFU} / \mathrm{ml}$ (24). MBCs were determined by transferring $100 \mu \mathrm{l}$ samples from clear wells onto agar plates without antibiotics. The MBC was the lowest concentration at which there was no visible microbial growth.

Large-scale preparation of recombinant VRB2B3. A single colony of $E$. coli containing the recombinant VRB2B3 plasmid was inoculated in Luria Bertani (LB) broth with kanamycin $(100 \mathrm{mg} / \mathrm{ml})$, with shaking at $37^{\circ} \mathrm{C}$ overnight. Plasmid DNA was extracted following large-scale alkaline lysis and precipitation by the spermine method (19), then suspended in sterile saline water and stored at $20^{\circ} \mathrm{C}$ until use.

Preparation of LP. Lecithin, cholesterol, octadecylamine, 1,2-dioleoyl-sn-glycero-3-phosphoethanolamine (DOPE) and dimethyldistearylammonium bromide (DDAB) were purchased from Sigma-Aldrich (Merck KGaA, Darmstadt, Germany).

A mixture of $3 \mathrm{mg}$ lecithin, $1.7 \mathrm{mg}$ cholesterol and $0.5 \mathrm{mg}$ octadecylamine (30:17:5 by weight) in $10 \mathrm{ml}$ chloroform was added to a $250 \mathrm{ml}$ round bottom flask and evaporated under vacuum in a rotary evaporator at $37^{\circ} \mathrm{C}$, forming a thin film on the inner surface. The $20 \mathrm{ml}$ of $\mathrm{ddH}_{2} \mathrm{O}$ was added at $37^{\circ} \mathrm{C}$ and the flask was shaken with intermittent sonication in a bath sonicator.

Preparation of nanoparticles using LP modified CS. Five different delivery systems (CS, PEG-O-CS-PEI, LP, PCL and PCL-protamine) with and without entrapped VRB2B3 (VRB2B3-CS, VRB2B3-PEG-O-CS-PEI, VRB2B3-LP, VRB2B3-PCL, VR B2B3-PCL-protamine) were prepared by the ionotropic gelation method (26). Briefly, biomaterials (CS, PEG-O-CS-PEI, LP, PCL and PCL-protamine) were diluted, respectively, by buffer $\mathrm{CH}_{3} \mathrm{COOH} / \mathrm{CH}_{3} \mathrm{COONa}$ (pH 5.5) containing triphosphate and heated for $10 \mathrm{~min}$ at $65^{\circ} \mathrm{C}$ with 
Table I. Primers of BD3 and BD2.

\section{Primer}

Sequence $\left(5^{\prime}-3^{\prime}\right)$

\begin{tabular}{ll}
\hline P1 & GCCATGGGAATCATAAACACATTACAGAAATATTATTGCAGAGTCAGAGGCGGC \\
P2 & AGAGTCAGAGGCGGCCGGTGTGCTGTGCTGAGCTGCCTTCCAAAGGAGGAACAGATCGGCAAG \\
P3 & GAACAGATCGGCAAGTGCTCGACGCGTGGCCGAAAATGCTGCCGAAGAAAGAAAAGCAGCGGT \\
P4 & GAAAGAAAAGCAGCGGTAGCGGAAGTGGTATAGGCGATCCTGTTACCTGCCTAAAGAGTGGAGC \\
P5 & TGCCTAAAGAGTGGAGCCATATGTCATCCAGTCTTTTGCCTCGTCGGTATAAACAAATTGGAACCTG \\
P6 & AAACAAATTGGAACCTGCGGTCTCCCTGGAACAAAATGCTGCAAAAAGCCATAAAGATCTGAATTCCG
\end{tabular}

$\mathrm{BD}, \beta$-defensin. mild magnetic stirring. Then, the solution of plasmid was added slowly to the solution of biomaterial drop by drop, and the mixed solution was remixed and left for $5 \mathrm{~min}$. The average diameter and zeta potential of the polymeric micelles were detected by Zetasizer 3000 HS/IHPL (Malvern Instruments Ltd., Malvern, UK).

Polyamine cationic liposomes (PCL) were prepared using $30 \mathrm{mg}$ DOPE, $10 \mathrm{mg}$ cholesterol and $10 \mathrm{mg}$ DDAB per round bottom flask and were used to produce PCL as described above. PCL/protamine formulations were prepared by adding protamine to the PCL $\left(\mathrm{V}_{\text {protamine }}: \mathrm{V}_{\mathrm{PCL}}=1.5: 1\right)$. CS $(95 \%$ deacylated, MW $=150 \mathrm{kDa})$ was supplied by Chengdu Organic Chemistry Institute of China Academy of Science; polyethyleneglycol-O-chitosan-polyethyleneimine (PEG-O-CS-PEI) was provided by the College of Chemistry of Sichuan University (25).

Agarose gel electrophoresis assay of nanoparticles. The DNA binding ability of biomaterials (CS, PEG-O-CS-PEI, LP, PCL and PCL-protamine) were evaluated by agarose gel electrophoresis. The nanoparticle solutions of plasmid DNA with biomaterials (CS, PEG-O-CS-PEI, LP, PCL and PCL-protamine) copolymer were loaded into individual wells of $0.7 \%$ agarose gel, electrophoresed at $100 \mathrm{~V}$ for $45 \mathrm{~min}$ and stained with $0.01 \%$ gold-view. The plasmid migration pattern was revealed under UV irradiation.

Transfection and efficiency analysis of fusion BD2/3 gene in eukaryotic cells in vitro. 293 cells (human embryonic kidney cells; ATCC no. CRL-1573TM) were purchased from the Chinese Academy of Science Cell bank (Shanghai, China). 293 cells were cultured in 6 well plates $\left(1.5 \times 10^{6}\right.$ cells/well $)$ for $24 \mathrm{~h}$ and grown in $2 \mathrm{ml}$ Dulbecco's modified Eagle's medium (DMEM; Invitrogen; Thermo Fisher Scientific, Inc., Waltham, MA, USA) containing $4.0 \mathrm{mM} \mathrm{L-glutamine,} 10 \% \mathrm{FBS}$, $100 \mathrm{U} / \mathrm{ml}$ penicillin and $100 \mu \mathrm{g} / \mathrm{ml}$ streptomycin (Thermo Fisher Scientific, Inc.), and maintained at $37^{\circ} \mathrm{C}$ in a $5 \% \mathrm{CO}_{2}$ humidified incubator (Sanyo Electric Co., Ltd., Tokyo, Japan) until the cell confluency of 293 achieved $80 \%$. The complexes of nanoparticles containing CS, PEG-O-CS-PEI, LP, PCL and PCL-protamine each containing $5 \mu \mathrm{g}$ VRB2B3 plasmid were added into each well to transfect cells, respectively. Then, the transfected cells were incubated for $48 \mathrm{~h}$ and the supernatants were collected for antibacterial bioactivity detection $(E$. coli and S. Pneumoniae) of fusion BD2/3.
Animal inoculation and challenge with nanoparticles. Sixty female 3-week-old healthy Kunming mice (Animal Center of Sichuan University) were randomly divided into 6 groups (5 treatment groups and an untreated control). Mice in the treatment groups were injected intramuscularly (quadriceps) with $150 \mu \mathrm{g}$ plasmids, respectively, in VRB2B3-LP (A group), VRB2B3-CS (B group), VRB2B3-PEG-O-CS-PEI (C group), VRB2B3-PCL (D group) or VRB2B3-PCL-protamine (E group). Controls received $150 \mu \mathrm{g}$ blank plasmid VR1020-CS. Blood samples were collected by tail vein 0, 7, 14 and 21 days post-injection (p.i.). Two weeks after injection, all the experimental mice were challenged intraperitoneally (i.p.) with

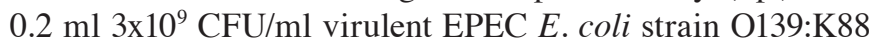
(Center of Animal Disease Control of Sichuan Province). Mice were euthanized at 28 days post-challenge.

The care and use of experimental mice fully complied with Chinese animal welfare laws, guidelines and regulations.

\section{Immunological assays of immunized mice}

Assay of IgG, IgGland IgG2a by sandwich ELISA. Total serum $\mathrm{IgG}$, IgG1 and IgG2a were measured by mouse Ig ELISA quantitation kits (Bethyl Laboratories, Montgomery, TX, USA) according to manufacturer's instructions. Capture antibody-coated 96-well plates were incubated with $100 \mu \mathrm{l}$ serially diluted sera samples and standards for $1 \mathrm{~h}$ at ambient temperature. HRP-conjugated goat anti-mouse secondary antibodies IgG, IgG1 and IgG2a were added to the wells in triplicate and incubated for $1 \mathrm{~h}$ at $37^{\circ} \mathrm{C}$. Absorbance was measured in a multi-functional microplate reader 680 (Bio-Rad Laboratories, Inc., Hercules, CA, USA) at $450 \mathrm{~nm}$.

Assay of IL-2, IL- 6 and IFN- $\gamma$ by sandwich ELISA. Serum IL-2, IL- 6 and IFN- $\gamma$ were assayed by mouse IL-2, IL-6 and IFN- $\gamma$ ELISA kits (eBioscience, San Diego, CA, USA), according to the manufacturer's instructions. The $\mathrm{OD}_{450}$ values of the samples were measured in triplicate by a microplate reader 680 (Bio-Rad Laboratories, Inc.).

Assay of immune cell quantity in the peripheral blood. The immune cells of mice were counted using an automatic Excell $^{\mathrm{TM}} 22$ blood cell counter (Denam Co., New York, NY, USA).

Assay of CD4 and CD8 T cells by FCM. Mouse anti-mouse CD4 and CD8 mAbs, labeled with fluorescein isothiocyanate (FITC) and R-phycoerythrin (R-PE), respectively, were purchased from SouthernBiotech (Birmingham, AL, USA). A total of $2 \mu \mathrm{l}$ of FITC-conjugated anti-CD4 and $2 \mu \mathrm{l}$ R-PE 


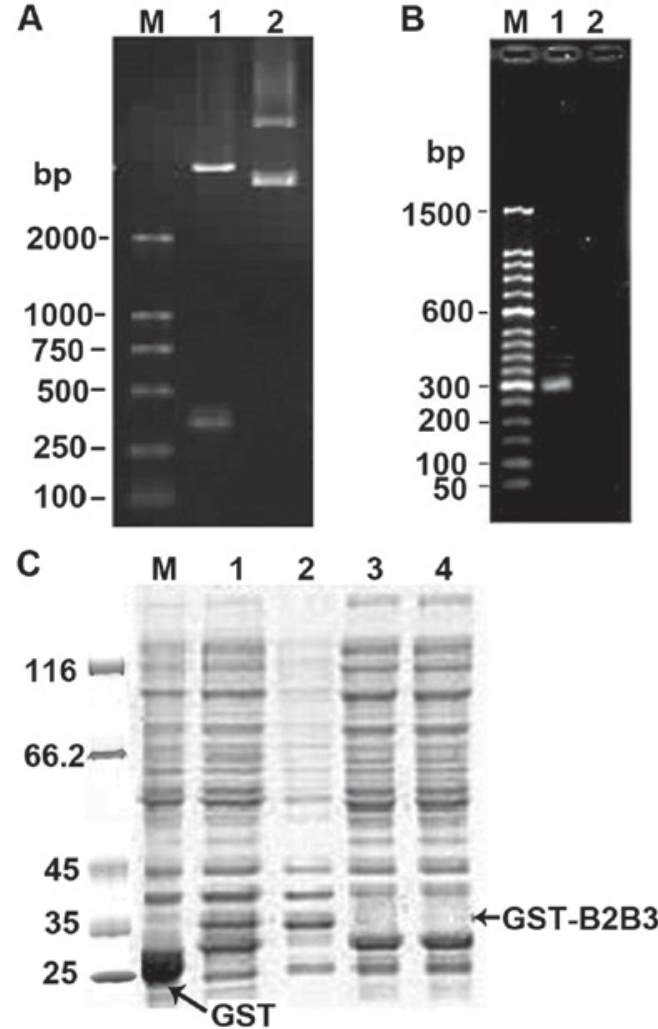

Figure 1.Electrophoretic and SDS-PAGE analysis of recombinant pGB2B3. (A) Electrophoretic identification of digested pGB2B3 recombinant $(1.0 \%$ agarose gel). Lane M, DL2000 marker; lane 1, pGB2B3/BamHI+EcoRI; lane 2, pGEX-4T-1 plasmid. (B) Electrophoresis of the PCR product from pGB2B3 (1.0\% agarose gel). Lane M, 50 bp marker; lane 1, PCR product of pGB2B3 plasmid; lane 2, PCR product of pGEX-4T-1 plasmid. (C) SDS-PAGE analysis of GST-tagged BD2/3 fusion protein expression. Lane M, protein MW marker; lane 1, expression products of pGEX-4T-1 induced by IPTG; lane 2, expression products of pGB2B3 induced by IPTG; lane 3, supernatant of lysed culture of pGB2B3 induced by IPTG; lane 4 , pellet of lysed culture of pGB2B3 induced by IPTG; lane 5, expression products of $\mathrm{pGB} 2 \mathrm{~B} 3$ without IPTG induction. $\mathrm{BD}, \beta$-defensin; IPTG, isopropyl- $\beta$-D-thiogalactopyranoside; GST, glutathione $\mathrm{S}$ transferase.

labeled anti-CD8 were added to $1.0 \mathrm{ml}$ EDTA-stabilized blood and incubated for $30 \mathrm{~min}$. Erythrocytes were lysed and the remaining cells were washed. Two-color-stained samples were analyzed using a FACScan flow cytometer (BD Biosciences, Franklin Lakes, NJ). Cells labeled with a single conjugated $\mathrm{mAb}$ served as controls. For each sample, $2 \times 10^{4}$ cells were analyzed by Cell-Quest ${ }^{\mathrm{TM}}$ software. The absolute numbers of each T subpopulation in peripheral blood were calculated as follows: absolute number $\left(10^{6} / \mathrm{ml}\right)=(\%$ positive cells of all cells analyzed x WBC)/100.

Statistical analysis. Data from all the groups were presented as mean \pm SD. Statistical analysis between groups was performed using Student's t-test. $\mathrm{P}<0.05$ was considered to indicate a statistically significant difference.

\section{Results}

Construction of fusion gene of BD2 and BD3. As shown in Fig. 1, a band of $\sim 300$ bp was detected by agarose gel electrophoresis following double digestion and plasmid PCR (Fig. 1A and B), indicating that fusion BD2/3 had been
Table II. The MIC and MBC of fusion BD2/3 antibacterial peptide.

\begin{tabular}{lcc}
\hline Bacterial strain & MIC $(\mu \mathrm{g} / \mathrm{ml})$ & MBC $(\mu \mathrm{g} / \mathrm{ml})$ \\
\hline S. aureus ATCC26112 & 2 & 4 \\
S. pneumoniae ATCC49619 & 2 & 8 \\
P. aeruginosa ATCC27853 & 2 & 8 \\
E. coli ATCC25922 & 2 & 8 \\
\hline
\end{tabular}

$\mathrm{BD}, \beta$-defensin; MIC, minimum inhibition concentration; MBC, minimal bactericide concentration.

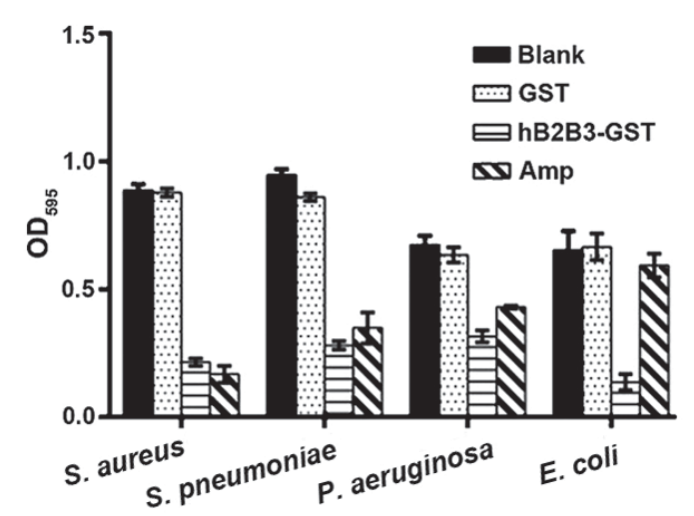

Figure 2. Antimicrobial activity of recombinant BD2/3 protein expressed by pGB2B3. BD, $\beta$-defensin.

successfully inserted into pGEX-4T-1 vector. Sequencing of pGB2B3 confirmed this result (data not shown). SDS-PAGE analysis (Fig. 1C) revealed that GST-tagged fusion proteins were successfully induced to express mainly in the supernatant of lysed cultures.

Antimicrobial activity of fusion BD2/3 protein in vitro. Fig. 2 and the values of MIC and MBC (Table II) demonstrated that the fusion $\mathrm{BD} 2 / 3$ protein induced by IPDG significantly inhibited the proliferation of Gram-positive bacteria (S. aureus, S. pneumoniae) and Gram-negative bacteria (P. aeruginosa, E. coli) in comparison with controls and the GST group $(\mathrm{P}<0.05)$. Compared with the ampicillin control group, the fusion BD2/3 protein had higher antimicrobial activity against Gram-negative bacteria. That means the fusion $\mathrm{BD} 2 / 3$ protein can be used as an anti-bacterial infection drug.

Characterization of nanoparticles. Observation by Zetasizer 3000 HS/IHPL (Malvern Instruments Ltd., Malvern, UK) revealed that most of the liposomes/polymer VRB2/3 were spherical nanoparticles ranging from $178-381 \mathrm{~nm}$ with zeta potentials $+11.1-22.1 \mathrm{mV}$ (Table III), confirming that the DNA was fully entrapped in the nanoparticles and indicating an almost $100 \%$ package rate. Through agarose gel electrophoresis assay of nanoparticles, the condensation capability of CS, PEG-O-CS-PEI, LP, PCL and PCL-protamine with DNA were evaluated by measuring the emitted fluorescence when adding the goldview into the nanoparticles. It was shown that 


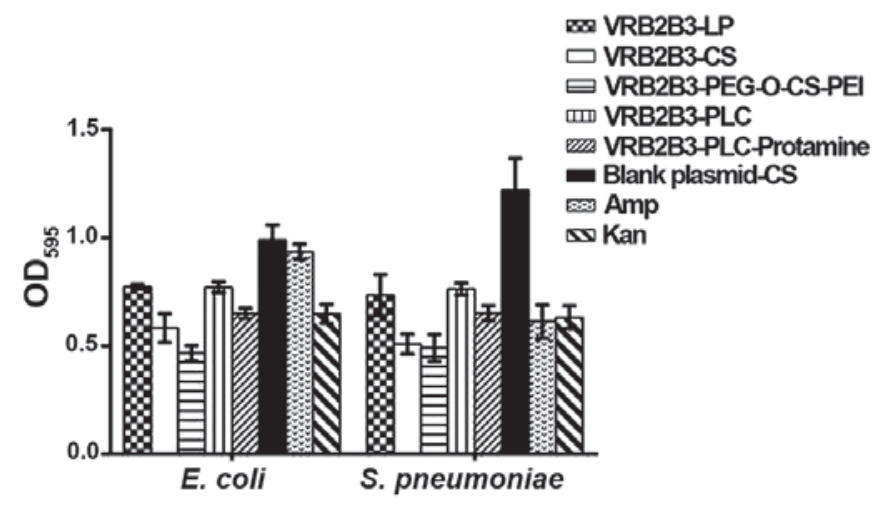

Figure 3. Comparison of the transfection efficiency of VRB2B3 among different gene delivery carriers.

the complexes were positively charged when the mass ratios were 20:1, while the migration of DNA plasmid was suppressed completely when the mass ratio of CS, PEG-O-CS-PEI, LP, PCL and PCL-protamine to DNA was 20:1. It showed that DNA plasmids were entrapped into CS, PEG-O-CS-PEI, LP, PCL and PCL-protamine successfully.

Expression efficiency of nanoparticles in vitro. Compared with those in the blank plasmid-CS control group, the antibacterial activity against $E$.coli and $S$.pneumoniae of $\mathrm{BD} 2 / 3$ significantly increased in VRB2B3-LP, VRB2B3-CS, VRB2B3-PEGO-CS-PEI, VRB2B3-PLC and VRB2B3-PLC-protamine
Table III. Size and zeta potential of the nanoparticles.

\begin{tabular}{lcc}
\hline Sample & Zeta potential $(\mathrm{mV})$ & Size (nm) \\
\hline VRB2B3-LP & $+17.8 \pm 0.62$ & $335 \pm 16.2$ \\
VRB2B3-CS & $+15.8 \pm 0.66$ & $230 \pm 12.3$ \\
VRB2B3-PEG-O-CS-PEI & $+21.9 \pm 0.92$ & $178 \pm 10.5$ \\
VRB2B3-PCL & $+22.1 \pm 0.69$ & $350 \pm 14.6$ \\
VRB2B3-PCL-protamine & $+11.1 \pm 0.33$ & $381 \pm 17.9$
\end{tabular}

LP, liposomes; CS, chitosan; PEG-O-CS-PEI, polyethylene glycol-Ochitosan-polyethylenimine; PCL, polyamine cationic liposomes.

groups $(\mathrm{P}<0.05)$. Furthermore, the antibacterial ability against E. coli of BD2/3 in VRB2B3-PEG-O-CS-PEI group was significantly higher than those in the other groups. The antimicrobial activity against $S$. pneumoniae was also significantly raised in VRB2B3-CS and VRB2B3-PEG-O-CS-PEI groups $(\mathrm{P}<0.05)$, though not significantly raised between them $(\mathrm{P}>0.05)$ (Fig. 3). These results demonstrated that VRB2B3 was successfully transfected into 293 cells by the five gene delivery systems, LP, CS, PEG-O-CS-PEI, PC and PCL-protamine. Of these, the expression efficiency of PEG-O-CS-PEI was the highest.

Quantitation of $\operatorname{Ig} G, \operatorname{Ig} G 1$ and $\operatorname{Ig} G 2 a$. The level of $\operatorname{IgG}$ significantly improved in sera of treated mice compared with that of the blank control from 21 days post-injection (p.i.), and
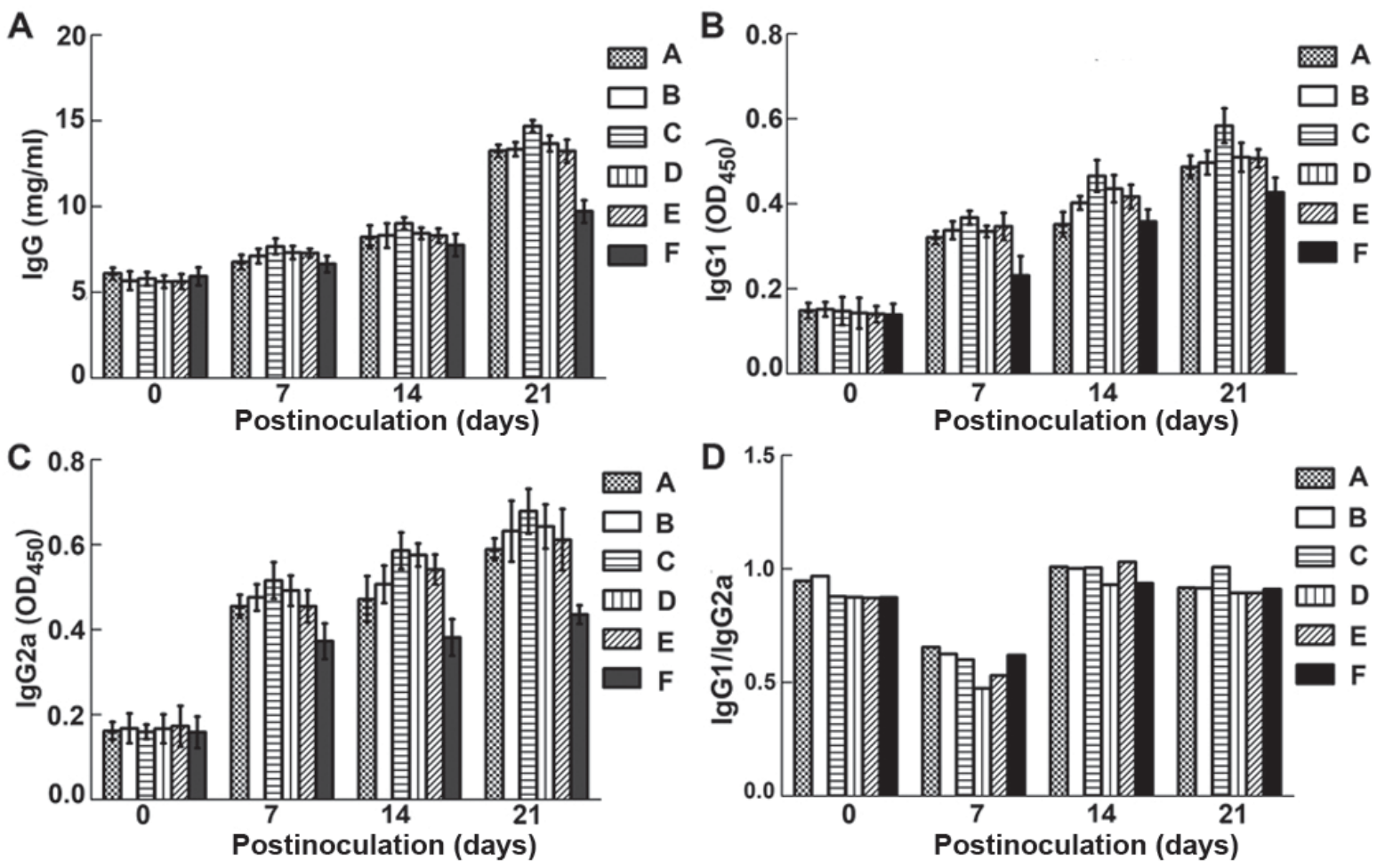

Figure 4. Levels of IgG (A), IgG1 (B) and IgG2a (C) in the sera of experimental mice. Group A, B, C, D and E were intramuscularly injected with VRB2B3-LP, VRB2B3-CS, VRB2B3-PEG-O-CS-PEI, VRB2B3-PCL and VRB2B3-PCL-protamine, respectively; group F was the blank control group. (D) IgG1/IgG2a. No obvious change was found compared with that in blank control group, which indicated Th1/Th2 homeostasis during the whole experiment. The sign ( $\downarrow$ ) indicates the challenge day with virulent EPEC E. coli. LP, liposomes; CS, chitosan; PEG-O-CS-PEI, polyethylene glycol-O-chitosan-polyethylenimine; PCL, polyamine cationic liposomes. 

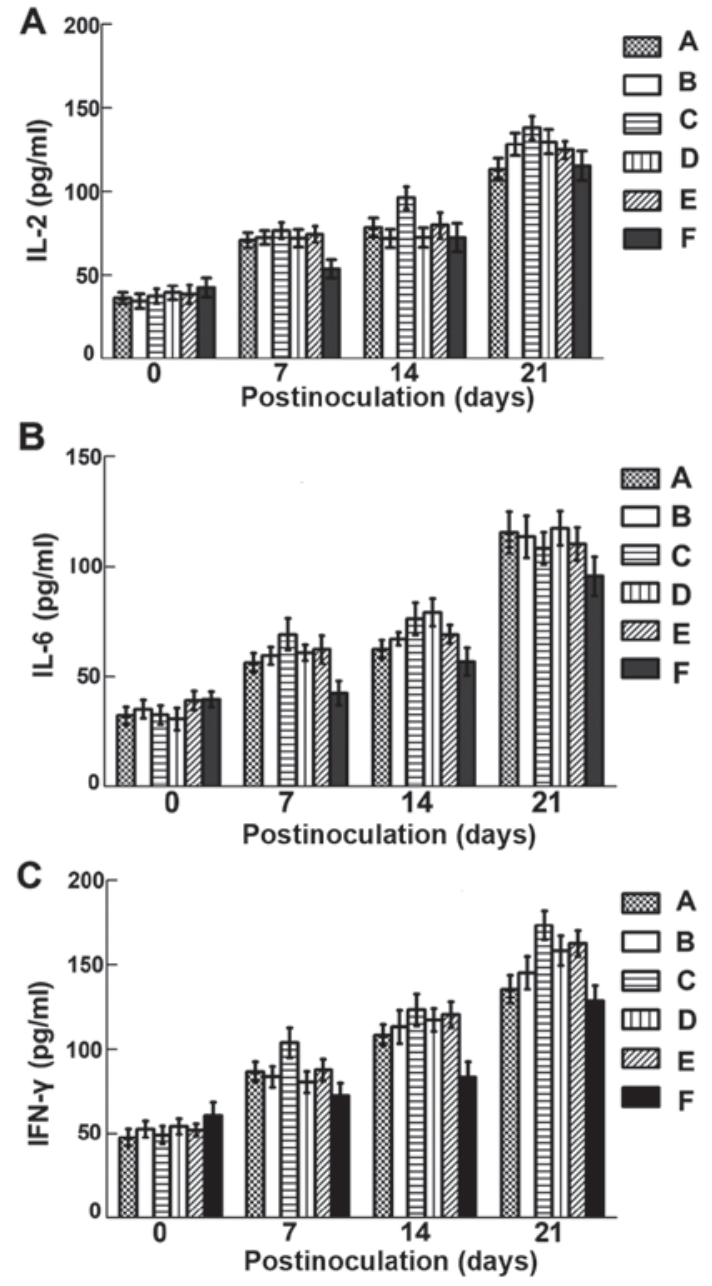

Figure 5. Changes of IL-2 (A), IL-6 (B) and IFN- $\gamma$ (C) in the sera of experimental mice.

IgG1 and IgG2a significantly increased from 14 days p.i. with the dominant increase in IgG2a $(\mathrm{P}<0.05)$, while there was no significant difference between treatment groups $\mathrm{A}$ to $\mathrm{E}$, the amount of $\mathrm{IgG}$, IgG1 and $\operatorname{IgG} 2 \mathrm{a}$ in group $\mathrm{C}$ was higher than those in the other groups (Fig. 4). Fig. 4D shows that there was no difference in $\mathrm{IgG1} / \mathrm{IgG} 2$ a ratios after intramuscular administration of plasmid nanoparticles.

Cytokine levels in treated mice. Compared with those of the controls, the levels of IL-2, IL-6 and IFN- $\gamma$ were significantly increased in the sera of treated mice from 7 days p.i. (Fig. 5; P<0.05). The levels of IL-2 and IFN- $\gamma$ of group $\mathrm{C}$ were higher than those in group $\mathrm{A}, \mathrm{B}, \mathrm{D}$ and $\mathrm{E}$, while the differences in groups $\mathrm{A}, \mathrm{B}, \mathrm{D}$ and $\mathrm{E}$ were not significant $(P>0.05)$. After challenged with virulent bacteria, cytokine levels in treated groups were still significantly higher than those in controls except for IL-2 at 14 days post-challenge.

Effect on immune cell numbers. Fig. 6A shows that lymphocyte numbers were significantly increased in treated mice from 7 days p.i. onwards $(\mathrm{P}<0.05)$, and remained high post-challenge. As shown in Fig. 6B and $\mathrm{C}$, neutrophil and monocyte counts were increased to different degrees following treatment except for neutrophils at 7 days post-challenge, but not significantly $(\mathrm{P}>0.05)$.
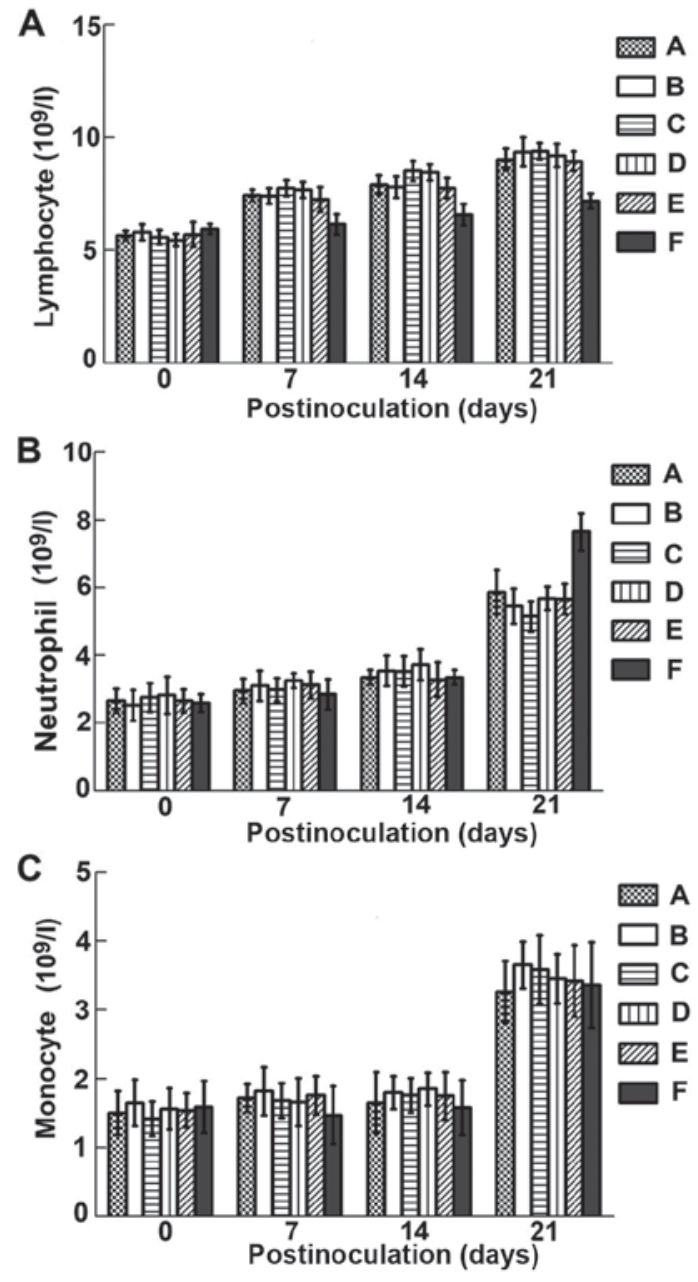

Figure 6. Effect on lymphocytes (A), neutrophils (B) and monocytes (C) in the blood of experimental mice.

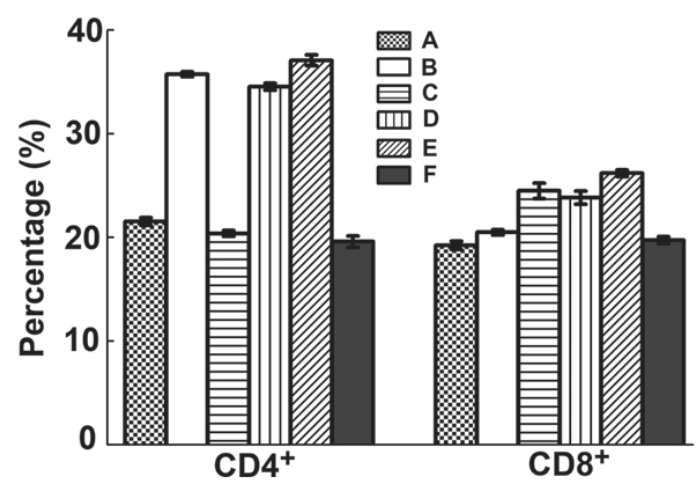

Figure 7. Changes of $\mathrm{T}$ cells in the peripheral blood of experimental mice.

Response to challenge

$C D 4$ and $C D 8$ positive $T$ cells. After challenge, levels of $\mathrm{CD} 4^{+}$ Th cells of B, D and E groups were significantly increased $(P<0.05)$ but it was not significant between groups $(P>0.05)$. $\mathrm{CD} 8^{+} \mathrm{Tc}$ cell counts were also significantly raised in group B, $\mathrm{C}, \mathrm{D}(\mathrm{P}<0.05)$ but again not significant between groups (P>0.05) (Fig. 7).

Detection of the post challenged mice. Following i.p. injection with virulent EPEC $E$. coli for 2 weeks, most mice injected 
Table IV. Effect of challenge with virulent EPEC E. coli.

\begin{tabular}{lcccc}
\hline Group & $\begin{array}{c}\text { Challenge } \\
\text { number }\end{array}$ & Morbidity & Mortality & $\begin{array}{r}\text { Survival } \\
\text { rate (\%) }\end{array}$ \\
\hline A & 10 & 2 & 2 & 80 \\
B & 10 & 1 & 0 & 100 \\
C & 10 & 0 & 0 & 100 \\
D & 10 & 1 & 1 & 90 \\
E & 10 & 1 & 1 & 90 \\
F & 10 & 10 & 10 & 0 \\
\hline
\end{tabular}

with VRB2B3 packaged in all the tested forms survived without symptoms while the controls became lethargic and developed severe diarrhea (Table IV). Moreover, gross pathological inspection showed that the organs and tissues of surviving treated mice were normal. In contrast, control mice died of infection presented with visible lesions, including necrosis of the liver and spleen, bleeding of the stomach, and duodenal and jejunal catarrh, with $E$. coli being isolated from the affected organs by microbiological culture.

\section{Discussion}

In this study, a novel fusion gene BD2/3 was successfully constructed, containing sequences from human BD-2 and BD3 genes, which individually had been found to exert significant antimicrobial ability and immunological stimulatory activity $(4,5,7)$. Fusion gene BD2/3 contained 304 bases and encoded 93 amino acids. The molecular weight of the BD2/3 expressed fusion protein was $11.2 \mathrm{kDa}$. We proved that this novel fusion protein displayed remarkable antibacterial bioactivity in vitro and immunological enhancement in vivo. By antimicrobial assay, the results have demonstrated a significant reduction of bacterial growth in vitro. Most notably, the antimicrobial activity of BD2/3 fusion protein against gram negative pathogen was more potent than that of ampicillin, indicating its potential as a candidate for new antibiotic drugs.

In BD2/3 plasmid-injected mice, the levels of IgG, IgG1 and IgG2a increased considerably, so as levels of IL-2, IL-6 and IFN- $\gamma$. Moreover, $\mathrm{CD} 4^{+} \mathrm{Th}$ and $\mathrm{CD}^{+} \mathrm{Tc}$ cell counts were also significantly elevated in all treated groups after EPEC E. coli challenge. These observations clearly showed that BD2/3 was able to promote the specific immune response in mice, and to provide robust immune protection of mice against pathogenic infection.

When treated mice were challenged i.p. with EPEC E. coli at 14 days p.i., levels of all measured parameters (immunoglobulins, interleukins and immune cells) were increased to different extents, illustrating the potent enhancement of immunity by $\mathrm{BD} 2 / 3$. Immune responses are mainly regulated by the activity of two functional $\mathrm{T}$ helper cell types, Th1 and Th2, Th1 cells primarily promote cellular immune responses and Th2 cells generally drive humoral immunity (27), and appropriate $\mathrm{Th} 2 / \mathrm{Th} 1$ balance is critical for maintenance of homeostasis. Many diseases are induced by the skewing of Th2/Th1 ratios (28). Dominant Th1 responses may contribute to diseases such as rheumatoid arthritis (RA) (29), multiple sclerosis (MS) (30) and type 1 diabetes (31). Atopic allergy is an example of Th2 dominance (32). The ratio of IgG1/IgG2a is usually interpreted as a reflection of different $\mathrm{T}$ helper cell (Th2-Th1) reactivity. Over the course of our experiments these ratios did not reveal any significant difference following treatment, indicating that BD2/3 did not influence Th2/Th1 balance. Therefore, we conclude that BD2/3 can enhance the immunity of mice to a remarkable degree and display the same biological safety as defensins in nature.

To raise the low efficiency of gene expression and to achieve stable effective gene delivery systems in vivo, the BD2/3 recombinant plasmid was incorporated into 5 different gene carriers: LP, CS, PEG-O-CS-PEI, PCL and PCL-protamine. Although there was no clear difference between them, except for better transfection efficiency and immune response in group C (VRB2B3-PEG-O-CS-PEI), all 5 carriers resulted in highly significant increased antibacterial bioactivity in HEK293 cells and enhancements of immunity both pre- and post-challenge. Based on these findings, it can be concluded that LP, CS, PEG-O-CS-PEI, PC and PCL-protamine are all effective gene delivery vectors in vitro and in vivo, while PEG-O-CS-PEI was the most effective and practicable. This may be attributed to the modification of PEI ligation on CS. PEI is known to improve transfection efficiency of genes in vivo by enhancing cellular endocytosis and escape from lysosomes, and its coupling with CS may extend the expression time of wrapped gene to prolong blood circulation time and reduce reticuloendothelial clearance. Previous studies from our laboratory have also shown that the expression efficiency of plasmids can be improved by entrapment with PEG-O-CS-PEI nanoparticles in vitro $(20,25)$.

Furthermore, none of the 5 treated mouse groups displayed any systemic or local symptom and lesion, such as local injuries in injected sites, fever or loss of weight gain following intraperitoneal challenge with EPEC E. coli. Whereas, control mice exhibited severe gross lesions. This indicates that the BD2/3-PEG-O-CS-PEI and other nanoparticles have the potential to be applied as safe and effective gene delivery systems.

In conclusion, our results suggest that the novel fusion BD2/3 is a safe and effective molecule not only to inhibit bacteria pathogens directly but also to enhance the immunity of mice against infection. In particular, the recombinant gene packed within PEG-O-CS-PEI nanoparticles has shown promise for development as a novel effective and biocompatible delivery system for control of infection caused by antibiotic-resistant pathogens.

\section{Acknowledgements}

We sincerely thank Dr Gang Wang (National Engineering Research Center for Biomaterials) for technical support.

\section{Funding}

This study was supported by the National Natural Science Foundation of China (no. 30871855), National International Cooperation Program (no. 2011DFA10101103) and key project from Sichuan Province of China (2016NYZ0042). 


\section{Availability of data and materials}

The datasets used and/or analyzed during the present study are available from the corresponding author on reasonable request.

\section{Authors' contributions}

$\mathrm{XW}, \mathrm{JC}, \mathrm{CC}, \mathrm{ZW}$ and RG conceived and designed the study. $\mathrm{XW}, \mathrm{JC}, \mathrm{CC}, \mathrm{HZ}, \mathrm{SZ}, \mathrm{JL}$ and XL were responsible for the collection and analysis of the patient data. XW, JC, ZW and RG interpreted the data and drafted the manuscript. CC and RG revised the manuscript critically for important intellectual content. All authors read and approved the final study.

\section{Ethics approval and consent to participate}

The study was approved by the Ethics Committee of Sichuan University (Chengdu, China).

\section{Patient consent for publication}

Not applicable.

\section{Competing interests}

The authors declare that they have no competing interests.

\section{References}

1. Norrby SR, Nord CE and Finch R; European Society of Clinical Microbiology and Infectious Diseases: Lack of development of new antimicrobial drugs: A potential serious threat to public health. Lancet Infect Dis 5: 115-119, 2005.

2. Hegstad K, Langsrud S, Lunestad BT, Scheie AA, Sunde M and Yazdankhah SP: Does the wide use of quaternary ammonium compounds enhance the selection and spread of antimicrobial resistance and thus threaten our health? Microb Drug Resist 16: 91-104, 2010.

3. Spellberg B, Blaser M, Guidos RJ, Boucher HW, Bradley JS, Eisenstein BI, Gerding D, Lynfield R, Reller LB, Rex J, et al; Infectious Diseases Society of America (IDSA): Combating antimicrobial resistance: Policy recommendations to save lives. Clin Infect Dis 52 (Suppl 5): S397-S428, 2011.

4. Ganz T: Defensins: Antimicrobial peptides of innate immunity. Nat Rev Immunol 3: 710-720, 2003.

5. Selsted ME and Ouellette AJ: Mammalian defensins in the antimicrobial immune response. Nat Immunol 6: 551-557, 2005.

6. Midorikawa K, Ouhara K, Komatsuzawa H, Kawai T, Yamada S, Fujiwara T, Yamazaki K, Sayama K, Taubman MA, Kurihara H, et al: Staphylococcus aureus susceptibility to innate antimicrobial peptides, $\beta$-defensins and CAP18, expressed by human keratinocytes. Infect Immun 71: 3730-3739, 2003.

7. Yang D, Biragyn A, Kwak LW and Oppenheim JJ: Mammalian defensins in immunity: More than just microbicidal. Trends Immunol 23: 291-296, 2002.

8. Yang D, Chertov O, Bykovskaia SN, Chen Q, Buffo MJ, Shogan J, Anderson M, Schröder JM, Wang JM, Howard OM, et al: $\beta$-defensins: Linking innate and adaptive immunity through dendritic and T cell CCR6. Science 286: 525-528, 1999.

9. Niyonsaba F, Iwabuchi K, Matsuda H, Ogawa H and Nagaoka I: Epithelial cell-derived human $\beta$-defensin- 2 acts as a chemotaxin for mast cells through a pertussis toxin-sensitive and phospholipase C-dependent pathway. Int Immunol 14: 421-426, 2002.

10. García JR, Jaumann F, Schulz S, Krause A, Rodríguez-Jiménez J, Forssmann U, Adermann K, Klüver E, Vogelmeier C, Becker D, et al: Identification of a novel, multifunctional $\beta$-defensin (human $\beta$-defensin 3) with specific antimicrobial activity. Its interaction with plasma membranes of Xenopus oocytes and the induction of macrophage chemoattraction. Cell Tissue Res 306: 257-264, 2001.
11. Cheng R, Feng F, Meng F, Deng C, Feijen J and Zhong Z: Glutathione-responsive nano-vehicles as a promising platform for targeted intracellular drug and gene delivery. J Control Release 152: 2-12, 2011.

12. Liu SP, Zhou L, Lakshminarayanan R and Beuerman RW: Multivalent antimicrobial peptides as therapeutics: Design principles and structural diversities. Int J Pept Res Ther 16: 199-213, 2010.

13. Gan Q, Wang T, Cochrane C and McCarron P: Modulation of surface charge, particle size and morphological properties of chitosan-TPP nanoparticles intended for gene delivery. Colloids Surf B Biointerfaces 44: 65-73, 2005.

14. $\mathrm{Li} \mathrm{L} \mathrm{and} \mathrm{Xu} \mathrm{B}$ : Multivalent vancomycins and related antibiotics against infectious diseases. Curr Pharm Des 11: 3111-3124, 2005.

15. Liu Z, Deshazer H, Rice AJ, Chen K, Zhou C and Kallenbach NR: Multivalent antimicrobial peptides from a reactive polymer scaffold. J Med Chem 49: 3436-3439, 2006.

16. Arnusch CJ, Branderhorst H, de Kruijff B, Liskamp RM, Breukink E and Pieters RJ: Enhanced membrane pore formation by multimeric/oligomeric antimicrobial peptides. Biochemistry 46: 13437-13442, 2007.

17. Young AW, Liu Z, Zhou C, Totsingan F, Jiwrajka N, Shi Z and Kallenbach NR: Structure and antimicrobial properties of multivalent short peptides. MedChemComm 2: 308-314, 2011.

18. Roy K, Mao HQ, Huang SK and Leong KW: Oral gene delivery with chitosan - DNA nanoparticles generate immunologic protection in a murine model of peanut allergy. Nat Med 5: 387-391, 1999.

19. Templeton NS, Lasic DD, Frederik PM, Strey HH, Roberts DD and Pavlakis GN: Improved DNA: Liposome complexes for increased systemic delivery and gene expression. Nat Biotechnol 15: 647-652, 1997.

20. Almofti MR, Harashima H, Shinohara Y, Almofti A, Baba Y and Kiwada H: Cationic liposome-mediated gene delivery: Biophysical study and mechanism of internalization. Arch Biochem Biophys 410: 246-253, 2003.

21. Xu Z, Wan X, Zhang W, Wang Z, Peng R, Tao F, Cai L, Li Y, Jiang Q and Gao R: Synthesis of biodegradable polycationic methoxy poly (ethylene glycol)-polyethylenimine-chitosan and its potential as gene carrier. Carb Polym 78: 46-53, 2009.

22. Li ZT, Guo J, Zhang JS, Zhao YP, Lv L, Ding C and Zhang XZ: Chitosan-graft-polyethylenimine with improved properties as a potential gene vector. Carb Polym 80: 254-259, 2010.

23. Horton RM, Hunt HD, Ho SN, Pullen JK and Pease LR: Engineering hybrid genes without the use of restriction enzymes: Gene splicing by overlap extension. Gene 77: 61-68, 1989.

24. Wiegand I, Hilpert K and Hancock RE: Agar and broth dilution methods to determine the minimal inhibitory concentration (MIC) of antimicrobial substances. Nat Protoc 3: 163-175, 2008.

25. Yu YY, Wang Z, Cai L, Wang G, Yang X, Li Y and Gao R: Synthesis and characterization of methoxy poly(ethylene glycol)O-chitosan-polyethylenimine for gene delivery. Carb Polym 81: 269-274, 2010.

26. Bodmeier R, Chen HG and Paeratakul O: A novel approach to the oral delivery of micro- or nanoparticles. Pharm Res 6: 413-417, 1989.

27. Mosmann TR and Sad S: The expanding universe of T-cell subsets: Th1, Th2 and more. Immunol Today 17: 138-146, 1996.

28. Kidd P: Th1/Th2 balance: The hypothesis, its limitations, and implications for health and disease. Altern Med Rev 8: 223-246, 2003.

29. Yamada H, Nakashima Y, Okazaki K, Mawatari T, Fukushi JI, Kaibara N, Hori A, Iwamoto Y and Yoshikai Y: Th1 but not Th17 cells predominate in the joints of patients with rheumatoid arthritis. Ann Rheum Dis 67: 1299-1304, 2008.

30. Lassmann H and Ransohoff RM: The CD4-Th1 model for multiple sclerosis: A crucial re-appraisal. Trends Immunol 25: 132-137, 2004.

31. Kis J, Engelmann P, Farkas K, Richman G, Eck S, Lolley J, Jalahej H, Borowiec M, Kent SC, Treszl A, et al: Reduced CD4+ subset and Th1 bias of the human iNKT cells in Type 1 diabetes mellitus. J Leukoc Biol 81: 654-662, 2007.

32. Seki Y,Inoue H, Nagata N, Hayashi K, Fukuyama S, Matsumoto K, Komine O, Hamano S, Himeno K, Inagaki-Ohara $\mathrm{K}$, et al: SOCS-3 regulates onset and maintenance of $\mathrm{T}(\mathrm{H}) 2$-mediated allergic responses. Nat Med 9: 1047-1054, 2003.

This work is licensed under a Creative Commons Attribution-NonCommercial-NoDerivatives 4.0 International (CC BY-NC-ND 4.0) License. 